\title{
PERSPECTIVAS DAS DISCUSSÕES SOBRE GÊNERO NAS POLÍTICAS EDUCACIONAIS: O DEBATE NO ÂMBITO DA ESCOLA TÉCNICA ESTADUAL HENRIQUE LAGE (ETEHL/FAETEC-RJ)
}

\author{
Andrea Peres Lima ${ }^{1}$ \\ Fundação de Apoio à Escola Técnica do Rio de Janeiro - FAETEC-RJ
}

Marcelo Farias Larangeira ${ }^{2}$

Escola Técnica do Rio de Janeiro - FAETEC-RJ

\begin{abstract}
Resumo
As políticas educacionais sobre gênero obtiveram mudanças significativas para consolidar direitos nos últimos doze anos, no entanto, em junho de 2014, discursos contrários a essas políticas na esfera da educação pública culminaram em uma intensa polêmica no cenário político brasileiro. Discursos da bancada conservadora alegavam que ao introduzir 'ideologia de gênero nas escolas' os conceitos de homem, mulher e família seriam deturpados e que assim caberia que o tema fosse discutido em seus lares com suas famílias. Nessa perspectiva, esse trabalho objetiva analisar se essa polêmica resultou na falta de legitimidade em se tratar a matéria nas escolas públicas.
\end{abstract}

Palavras-chave: Gênero; Política Educacional; Polêmica; Análise do Discurso.

\section{PERSPECTIVES OF DISCUSSIONS ON GENDER IN EDUCATIONAL POLICIES: THE DEBATE IN THE CONTEXT OF STATE TECHNICAL SCHOOL HENRIQUE LAGE (FAETEC-RJ)}

\begin{abstract}
Gender educational policies have undergone significant changes to consolidate rights in the last twelve years. However, in June 2014, discourses contrary to these policies in the sphere of public education culminated in an intense controversy in the Brazilian political scene. Discourses of the conservative panel argued that introducing 'gender ideology in schools' the concepts of man, woman and family would be misrepresented and that it would therefore be appropriate for the subject to be discussed in their homes with their families. In this perspective, this work aims to analyze if this controversy resulted in the lack of legitimacy in treating the matter in public schools.
\end{abstract}

Keywords: Gender. Educational policies. Controversy. Discours analysis.

\footnotetext{
${ }^{1}$ Especialista em Linguística pela Faculdade de Letras da Universidade Federal Fluminense (UFF/RJ). Graduada em Letras - Universidade do Estado do Rio de Janeiro (UERJ). Professora de Língua Inglesa da Fundação de Apoio à Escola Técnica do Rio de Janeiro (FAETEC-RJ).

${ }^{2}$ Doutorando em Ciências Jurídicas e Sociais (PPGSD - UFF). Faculdade de Direito - Universidade Federal Fluminense (UFF-RJ). Mestre em Ciências Jurídicas e Sociais pelo Programa de Pós Graduação em Ciências Jurídicas e Sociais (PPGSD-UFF). Professor de Direito Civil e Empresarial do Curso de Graduação em Direito Departamento de Ciências Jurídicas da Universidade Salgado de Oliveira (UNIVERSO) - Campus de São
} Gonçalo/RJ.

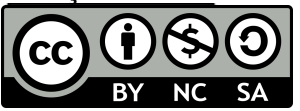




\section{INTRODUÇÃO}

A presente pesquisa surgiu num momento em que as discussões acerca do debate sobre gênero em sala de aula faziam parte não somente dos discursos midiáticos televisivos, mas se tornaram também, entre os estudantes da Escola Técnica Estadual Henrique Lage (ETHEL), discussões calorosas que ecoavam pelos corredores e pátio dessa instituição. Nesse solo fértil de intensas discussões e de uma demanda por parte do próprio material didático adotado pela referida escola falar sobre esse tema tornou-se um momento de tamanho conflito em sala de aula. Ora pois, havia aqueles definitivamente contra o debate e que clamavam que logo assim que o projeto Escola Sem Partido entrasse em vigor, eles poderiam fazer algo para evitá-lo.

Pesquisar auxilia na observação do mundo e como consequência um "novo" olhar sobre ele é propiciado. Dentro dessa perspectiva, é que embrionariamente brotou a necessidade de investigar o quão influenciados esses enunciados proferidos foram pelos discursos midiáticos e se efetivamente houve essa influência de quais instituições eles provêm. Outra reflexão que emerge é se essa 'polêmica' do debate de gênero na escola retira a legitimidade do professor ao tratar desse assunto, vez que na legislação atual brasileira existem normas cujo teor permite tal abordagem didática. Assim, foi realizada a coleta de dados entre os alunos, através de questionários abertos e fechados, com o objetivo de perceber a visão que os entrevistados possuíam acerca do tema em questão. E, por conseguinte, estas informações poderem ser analisadas a partir da ótica da Análise do Discurso.

Desta maneira, a partir das formações discursivas que integram esse campo discursivo dos questionários, estabelecer um universo discursivo, onde seja possível delinear e apontar os motivos que tornam tão polêmico a referida discussão em sala de aula. Também foram utilizados casos concretos provenientes de jornais e notícias que tramitam na rede mundial de computadores. Esses casos abordam conflitos que foram suscitados a partir dessa 'polêmica' da discussão de gênero na escola. Esses casos exemplificam as demandas que timidamente começam a chegar ao Poder Judiciário para que este defina o que não ficou claro com a mudança no Plano Nacional de Ensino. Tal análise é de grande relevância para a construção de um possível paradigma na esfera do poder judiciário futuramente, todavia insta enfatizar, que esses posicionamentos que advirão dos julgamentos dessas demandas contribuirão, entretanto, não de forma ideal, tendo em vista a construção do conhecimento quando construído intersubjetivamente, logo que não pode deixar de ser considerado no decorrer desse trabalho.

Nesse diapasão, através da análise do discurso aplicada aos questionários abertos um novo questionamento foi trazido à baila: se a retirada do termo 'gênero' gera aniquilação de 
direitos sob o ponto de vista de Juergen Habermas, cujas reflexões corroboram para a pluralidade de direitos no Estado Democrático Brasileiro.

\section{A QUESTÃo DO DEBATE DE GÊNERO NO CENÁRIO POLÍTICO E SOCIAL}

Esse polêmico paradigma, que a sociedade escolar está enfrentando, diante do contexto político vivido, traz indagações que não podem ser ocultadas. Isso porque conflitos de natureza ideológica cultural, política, racial e de gênero não deixarão de acontecer nos corredores, nas salas de aula e nos espaços de entretenimento da Escola Técnica Estadual Henrique Lage (ETEHL), situada em Niterói, pertencente à Fundação de Apoio à Escola Técnica (FAETEC), somente porque foram retiradas das diretrizes e metas educacionais.

Na turma de $3^{\circ}$ ano do ensino médio (EM) do curso técnico de edificações, onde essa pesquisa foi viabilizada, foi possível analisar e observar o quão importante e polêmico o tema de gênero é na vida político-social escolar. No entanto, nesse ambiente o tema de gênero não é só algo para a discussão, mas também uma realidade vivida por seus integrantes cotidianamente. Nessa turma, a diversidade religiosa, política, cultural e de gênero é bastante acentuada, visto que esse curso é oferecido apenas pela rede FAETEC nesse campus específico, e assim atraindo alunos fora dos limites do município de Niterói, o que torna o rol de alunos matriculados consideravelmente diversificado do ponto de vista político, cultural, socioeconômico e religioso. Essa questão polêmica tem sido o enfoque de calorosos conflitos no âmbito estadual e municipal desde junho de 2014, quando parlamentares retiraram o termo 'gênero' da proposta de reforma do Plano Nacional de Educação (PNE) que tramitava no Congresso Nacional para estabelecer diretrizes e metas na educação no período de vigência entre 2014 e 2024.

Nesse contexto, alegava-se que ao introduzir 'a ideologia de gênero nas escolas', os conceitos de homem, mulher e da família tradicional seriam deturpados. Desta maneira, o termo gênero foi retirado do PNE e transformou a erradicação da desigualdade racial, regional, de gênero e de orientação sexual dentro do contexto escolar em um objetivo genérico de erradicação de todas as formas de discriminação. A contrário senso, no final de 2014, parlamentares favoráveis à inclusão de gênero no PNE trouxeram à tona essa discussão na Conferência Nacional de Educação (CONAE), a qual contou com a participação de 3,9 mil cidadãos incluindo: participação popular, cooperação federativa e regime de colaboração de educadores de diversas esferas. 
O documento resultante dessa conferência traz em seu seio a proposta de uma política educacional pública popular, laica e com qualidade social, que colabore para banir diversas formas de preconceitos incluindo os de gênero. Apesar dessa tentativa, a supressão do vocábulo prosperou suscitando a possibilidade de os entes federativos incluírem em suas metas e diretrizes políticas de combate à discriminação de gênero de forma livre. Cedendo à pressão de diversos setores conservadores, relevante número de câmaras municipais e assembleias legislativas vetaram a inclusão do tema nas metas.

Essa 'polêmica' fez parte dos encontros matutinos, nos quais o debate sobre o tema sempre transformava a sala de aula em uma arena. Este grupo de alunos, que estava prestes a concluir o ensino médio era composto de alunos bastante atentos às notícias políticas. Importante mencionar que alguns eram muito ligados a aspectos religiosos, enquanto outros eram desprovidos de valores religiosos tão consistentes. Uns se mostravam liberais e defendiam a ideia de um estado mínimo, enquanto outros pareciam influenciados por discursos de esquerda. Vale ressaltar, que todos se mostravam interessados em opinar acerca do assunto. Com a aplicação dos referidos questionários para coleta de opinião da comunidade discente do campus da ETHEL chegou-se as determinantes abaixo:

Tabela 1: Formações discursivas observadas.

\begin{tabular}{|l|l|l|l|}
\hline Formações Discursivas & Favoráveis & Desfavoráveis & Não opinaram \\
\hline $\begin{array}{l}\text { "Eu acho que este tipo de discussão só } \\
\text { deve acontecer em casa" }\end{array}$ & 12 & 9 & 4 \\
\hline $\begin{array}{l}\text { "A discussão de gênero na escola é } \\
\text { importante para que promova o fim do } \\
\text { preconceito" }\end{array}$ & 18 & 7 & - \\
\hline $\begin{array}{l}\text { "A discussão sobre gênero pode } \\
\text { influenciar na opção sexual" }\end{array}$ & 9 & 13 & 3 \\
\hline
\end{tabular}

Convém mencionar que, ao serem indagados a respeito do conceito de gênero nenhum entrevistado reuniu o conceito tradicional (homem e mulher) e social /psicológico (o que diferencia socialmente as pessoas) em uma só resposta.

Tabela 2: Respostas observadas X universo entrevistado.

\begin{tabular}{|l|l|}
\hline Respostas & Alunos \\
\hline $\begin{array}{l}\text { "Aquilo que diferencia homem de mulher, gênero masculino de } \\
\text { feminino" }\end{array}$ & 10 \\
\hline "Identificação sexual" ou relacionado à sexualidade & 5 \\
\hline Não souberam ou não quiseram responder & 8 \\
\hline Conceito relacionado à biologia & 1 \\
\hline Relacionaram a um grupo social & 1 \\
\hline "Mencionaram que esse conceito é algo construído pela sociedade" & 0 \\
\hline
\end{tabular}

Dos 10 alunos que responderam que gênero é aquilo que diferencia homem de mulher, gênero feminino de masculino também incluíram no conceito o vocábulo: 
Tabela 3: O número de incidências observadas: Palavras "raça" e "homossexual" nas respostas dos entrevistados.

\begin{tabular}{|c|c|}
\hline Raça & 2 \\
\hline Homossexual & 2 \\
\hline
\end{tabular}

Diante do exposto, é possível deduzir que o conceito de gênero nessa turma de adolescentes entre 16 e 18 anos - que está prestes a ingressar em uma universidade - ou não foi exposto de forma apropriada ou se foi, os entrevistados não concordam com as nuances que diferem do conceito tradicional. É relevante aludir que um pequeno número de alunos incluiu ao conceito de gênero à questão racial, o que pode denotar a falta de informação a respeito do tema.

\section{AS FORMAÇÕES DISCURSIVAS SOB A PERSPECTIVA DA ANÁLISE DO DISCURSO}

A pesquisa desenvolvida teve como escopo apontar, a partir de uma prática discursiva, as formações favorável e desfavorável ao debate de gênero na ETEHL. Para isso, os estudos da Análise do Discurso foram abordados com o intuito de identificar com quais simulacros as respectivas formações discursivas dialogam quando em relação consigo mesmas e em oposição. Conforme o disposto, utilizou-se o conceito da Análise do Discurso que ultrapassa a pura e simples análise do texto e entenderemos por discurso "uma dispersão de textos, cujo modo de inscrição histórica permite definir como um espaço de regularidades enunciativas" (MAINGUENEAU, 2008, p. 15). Os enunciados, dentro da ótica do dialogismo de Bakhtin, constroem-se através das relações intersubjetivas e também subjetivas. Os enunciadores são substituídos por diferentes vozes que fazem deles sujeitos históricos e ideológicos (FIORIN, 2002, p. 50.).

Para D. Maingueneau (2008), essa relação de intersubjetividade e subjetividade é inscrita numa relação fortemente entrelaçada, a qual ele chama de o 'Mesmo' do discurso e seu 'Outro'. Sua hipótese floresce na concepção da heterogeneidade constitutiva, que é aquela, que, diferentemente da heterogeneidade mostrada, não deixa marcas identificáveis visualmente. São enunciados que estão tão entranhados ao texto que não podem ser compreendidos por uma abordagem linguística 'stricto sensu' e para essa tarefa o linguista francês propõe a hipótese do 'Primado do Interdiscurso'. Nesse sentido, interdiscurso é definido como uma tríade: universo discursivo, campo discursivo e espaço discursivo, na qual cada um deles está inserido no outro respectivamente. O universo discursivo é o conjunto de formações discursivas de todos os tipos que se relacionam dentro da ótica enunciativa. Campo discursivo é a zona de concorrência entre 
os enunciados, nela estão inseridos tanto os discursos que se confrontam, quanto aqueles que formam uma aliança. Dentro do campo discursivo, espaços discursivos devem ser delimitados, ou seja, formações discursivas que são relevantes para destacar hipóteses fundadas sobre um conhecimento textual e um saber histórico, que serão confirmadas conforme a progressão da pesquisa. Assim sendo, ao tomarmos como exemplo, as formações discursivas citadas anteriormente nos questionários, será possível notar a oposição entre elas. Seus enunciados dialogam entre si apresentando razões para o ponto de vista que acreditam estarem presentes no 'Outro' dos seus enunciados antagônicos.

Em outras palavras, esses enunciados do Outro só são compreendidos no interior do fechamento semântico do intérprete para; construir e preservar sua identidade no espaço discursivo, o discurso não pode haver-se com o Outro como tal, mas somente com o simulacro que dele constrói (MAINGUENEAU, 2008, p. 15).

Através de uma análise bem rasa, é possível vislumbrar a oposição entre a formação discursiva desfavorável (F1), cujos enunciados se opõem àqueles que defendem que se discutida na escola a questão de gênero poderá ajudar no combate desse preconceito (F2). Nesse sentido, em F1 o sema 'família' é positivo. Dentro da perspectiva interdiscursiva, este se coloca em oposição com os supostos semas negativos resultantes dos enunciados de seu 'Outro'. Vez que supostamente são a favor da homossexualidade e assim contrários aos bons costumes da família tradicional brasileira. Vale ressaltar que os enunciados de F1 desconsideram qualquer outro conceito de família diferente do modelo 'tradicional': pai, mãe e filhos. Hodiernamente devido à mudança nos valores em nossa sociedade, tornou-se importante uma definição mais ampla para o significado de família. Por isso, a suprema corte brasileira consagrou interpretação consolidada em referência ao dispositivo constitucional do artigo 226, que traz a família como base da sociedade e concebe especial proteção a família como um núcleo doméstico, o qual não se importa se constituída formal ou informalmente, ou se constituída por casais heteroafetivos ou pares homoafetivos. A partir do texto constitucional, é possível inferir que os enunciados oriundos de F1 possivelmente são influenciados por discursos religiosos. Estes traduzem os enunciados de $\mathbf{F} 2$ negativamente como se o tema gênero estivesse somente ligado à questão da homossexualidade - assunto condenado pelas instituições religiosas brasileiras. Contraditoriamente, os enunciados de F2 direcionam seu enfoque para a questão da mulher na sociedade. Nesta atividade dialógica interdiscursiva com seu 'Outro', os enunciadores de F2 precisam demonstrar e encontrar uma seara argumentativa antagônica aos enunciados de F1. Nesse sentido, trazem à tona a questão do preconceito contra a mulher. Fato este, que não pode ser contestado, visto que graças à luta dos movimentos feministas, a mulher tem a cada dia conseguido galgar degraus em uma sociedade tão patriarcal quanto a nossa. 


\section{O FENÔMENO DA INTERINCOMPREENSÃO DA POLÊMICA}

Nesse campo discursivo onde os enunciados forma produzidos por sujeitos que trazem experiências marcadas por um conteúdo histórico e ideológico foi possível determinar um espaço de regularidades enunciativas que se mantém sempre dentro do mesmo campo semântico. Além disso, cabe ressaltar que o debate embora regrado sempre caminhava para âmbito do convencimento do outro e nunca para uma troca de saberes onde o crescimento consciente e um exercício com o fim de esclarecimento e emancipação fossem estabelecidos. Percebe-se, também, que dentro de uma perspectiva linguística a ser exposta no seio do presente artigo, existe uma dissonância no pensamento dos entrevistados, haja vista os enunciadores ora se colocam contra a abordagem do tema na escola, ora parecem concordar.

Neste diapasão, levantam-se indagações acerca dessa heterogeneidade enunciativa presente no interdiscurso dos entrevistados, que leva à análise de duas formações discursivas divergentes que integram os enunciados referentes aos discursos presentes na polêmica da questão de gênero. Assim sendo, através dessa interpelação de simulacros conciliáveis e contraditórios, uma faceta do fenômeno da polêmica foi evidenciada: Como poderia uma pessoa ao mesmo tempo se colocar contra o debate de gênero na escola, e achar que esse debate na escola pode ser uma forma de diminuir o preconceito em nossa sociedade?

Assim, é curioso ressaltar que a maioria dos entrevistados acredita que a discussão de gênero só deve acontecer em casa, mas também a maioria acredita que a discussão de gênero na escola seja importante para promover o fim do preconceito de gênero. Por último, mas não menos importante, a maioria acredita que essa discussão sobre gênero não influencia na opção sexual. Neste cenário paradoxal, é que são suscitadas indagações sobre os discursos proferidos pelos entrevistados. Primeiramente, é incontestável que seus discursos são predominantemente parecidos aos discursos midiáticos televisivos, os quais não se colocavam efetivamente contra a questão da opção sexual, 'simplesmente' esses enunciados não deveriam ser expostos no âmbito público, mas no âmbito privado da família. Ocorre que ao analisá-los em sua materialidade, suas opiniões são controversas entre si, considerando- se as formações discursivas favoráveis e desfavoráveis na perspectiva do interdiscurso.

No nível em que situamos, a noção de polêmica' não coincide com o que habitualmente entendemos por isso (uma controvérsia violenta), que é apenas um dos aspectos de um fenômeno mais geral, o das relações explícitas entre duas formações discursivas (MAINGUENEAU, 2008,p.105).

Ora pois, o fenômeno da polêmica gera uma dupla interincompreensão que atravessa o espaço discursivo, no qual o discurso segundo se constitui contra o primeiro, assim a polêmica 
não advém do exterior, ela atinge uma extensão tal que não há mais valor informativo (MAINGUENEAU, 2008, p.107). Ela “[...] se sustenta com base na convicção de que existe um código que transcende os discursos antagônicos, reconhecido por eles, que permitiria decidir entre o justo e o injusto" (MAINGUENEAU, 2008, p.111). Assim, ao se analisar tais pressupostos, o conceito de duplipensamento presente na obra 1984 de George Orwell emerge a lógica da tentativa de analisar como enunciados tão divergentes podem conviver em harmonia ao expressar criticamente uma opinião sobre determinada polêmica. $\mathrm{O}$ duplipensar, segundo o autor, no próprio romance, “[...] significa a capacidade de abrigar simultaneamente na cabeça duas crenças contraditórias, e acreditar em ambas" (Orwell, 2009, p.188). Esse processo precisa ser consciente, ou não seria conduzido com a necessária precisão, mas também precisa ser inconsciente, do contrário traria consigo um sentimento de falsidade e, portanto, de culpa, ao por exemplo, desconsiderar que as pessoas têm a liberdade de optar por sua escolha sexual e que de qualquer forma estariam corroborando para a disseminação de um pensamento preconceituoso. Sob a égide do duplipensar, as pessoas não são capazes de tecer críticas àquilo que está sendo reproduzido pelo poder e é nessa ótica que esses protagonistas continuam a reproduzir discursos sem a "[...] coragem de fazer uso de seu entendimento", não permitindo libertar-se via uso da razão que leva ao esclarecimento e ao abandono da "[...] menoridade, que é a incapacidade de fazer uso de seu entendimento sem a direção de outro indivíduo" (HANSEN, 1999, p. 73). É notório que, na repercussão da polêmica da retirada do termo 'gênero' do PNE, existe uma ofensa a preceitos constitucionais que asseguram a liberdade de aprender e ensinar, pesquisar e divulgar o pensamento, a arte e o saber. Outrossim, fere-se ao pluralismo de ideias e de concepções pedagógicas que ainda não foram amplamente conquistados. É nessa marcha, ao abafar o diálogo de determinado assunto na esfera pública que a pluralidade no estado democrático de direito começa a ser ameaçada. Ademais, a ausência da permissão do debate específico da questão na escola, se direciona para a manipulação da realidade de nossa sociedade; mas graças ao exercício do duplipensamento, a sociedade também se convence de que o pluralismo e a liberdade não estão sendo violados, tão pouco não se está colaborando para práticas que coíbem condutas que vão de encontro a que a maioria julga 'moral'. Cultivou-se a ideia que o debate sob essa questão foi promovido suficientemente através da veiculação da informação midiática manipulada de instituições com interesses conservadores. E as pessoas, que só analisaram a polêmica sob a perspectiva construída pelos poderosos, acreditam que detêm conhecimento necessário para construir uma visão emancipada sob determinado assunto. No entanto, em “[...] nossa sociedade, aqueles que estão mais 
informados sobre o que ocorre são também os que estão mais longe de ver o mundo como ele é” (FIORIN, 2002, p. 188).

\section{ANÁLISE DO INTERDISCURSO DO SEMA FAMÍLIA NAS FORMAÇÕES DISCURSIVAS}

Através do mencionado acima, torna-se evidente que nesse exercício interdiscursivo, outros argumentos vão se estabelecendo e consubstanciando. Atinge-se um ponto em que não há mais convergência entre eles, e assim determinados discursos são impostos à sociedade. Desde o século XVI se discute o problema do governo das almas e das condutas, do governo das crianças e da problemática central da pedagogia. Governar um Estado significa, entre outros aspectos, ter em relação aos comportamentos individuais e coletivos uma forma de vigilância, de controle tão atenta quanto a do pai de família (FOUCAULT, 1998, p.279). Dentro de uma sociedade existem muitos governos: o do pai de família, o do superior do convento, o do pedagogo e o do professor em relação à criança e ao discípulo (FOUCAULT, 1998, p.277).

Todos esses governos integram o âmbito do governo central, cada um desenvolvendo funções específicas sob o controle de um governante escolhido democraticamente pelo sufrágio universal. Interessante notar, que hodiernamente o discurso que predomina é o da discussão do tema de gênero no interior das famílias, e não mais no âmbito escolar. Desta forma, a pergunta que vem à tona é que forças estão por trás desses preceitos jurídicos que vêm timidamente através de estruturas da linguagem dando forma à ordem das coisas (FOUCAULT, 2013, p.81).

Talvez ainda seja prematuro afirmar que serão desastrosos os resultados a partir do ponto de vista educacional da construção do pensamento livre e da pluralidade de ideias, pois o cenário político que o Brasil enfrenta ainda se encontra caótico e a efetiva ordem estabelecida com a mudança das diretrizes e metas educacionais ainda não se estabeleceu de forma plena nas instituições educacionais. O sema Família foi comum em uma série de manifestações públicas ocorridas naquele período. Em nome da ordem e da família um regime totalitário foi legitimamente instituído naquele momento de divergência ideológica no cenário político brasileiro. O núcleo familiar é onde o poder é menos visível, vez que, quando se pensa em família se pensa em relações afetivas e não em relações de poder. Assim sendo, é nessa instituição em que é menor a possibilidade de perceber esse controle, pois é onde ele se deixa ver menos "onde ele é mais completamente ignorado, portanto, reconhecido o poder simbólico é com efeito esse poder invisível o qual só pode ser exercido com a cumplicidade daqueles que não querem saber que lhe estão sujeitos ou mesmo que o exercem" (BOURDIEU, 1989, p.7). 
Esses sistemas simbólicos se fazem possíveis no campo discursivo como instrumentos de conhecimento e comunicação, pois fazem parte de um poder estruturante que é estruturado nos integrantes de uma sociedade. O desmantelamento de um sistema educacional é uma das formas mais cruéis do exercício desse poder simbólico, que é um poder de construção da realidade a partir de uma concepção homogênea do tempo, do espaço, do número, da causa, que torna possível a concordância entre as inteligências (BOURDIEU, 1989, p.9). Essas modificações legislativas não são acidentais e não resultam da mera hipocrisia, é um resultado deliberado de um vasto sistema de logro mental, que tende a se perpetuar como uma estratégia de governo, até o dia em que nós enquanto sociedade entendamos a necessidade do debate democrático de determinadas questões, tais como o debate de gênero, e a instituição de políticas que possibilitem o consenso entre as diferenças e não a tolerância, o respeito e a aceitação, vocábulos que se originam de um discurso religioso, entretanto que não corroboram para o bem viver e o sentimento de justiça social tão almejados.

\section{EFEITO E PERSPECTIVA DA POLÊMICA: (I)LEGITIMIDADE EM SE TRATAR DO TEMA}

É factível que esse momento na política brasileira é um momento de ruptura, especialmente, nos enunciados discursivos que tramitavam no espaço público antes dos acontecimentos de junho de 2014. Habermas (1980) afirma que as ocorrências de crises surgem de problemas não resolvidos e quando a estrutura de um sistema social não proporciona possibilidade para resolvê-los. Nesse sentido é que as crises são vistas como distúrbios persistentes, pois na maior parte das vezes não são produzidas através de mudanças acidentais, mas através de imperativos sistêmicos (HABERMAS, 1980, p. 13). Nessa perspectiva, é que emergiram os discursos que colocam em cheque a legitimidade de se tratar a questão de gênero em escolas da rede pública, vez que apesar de não serem proibidos por lei, criou-se um malestar através dessa polêmica que não mais encontra enunciados convergentes que produzam um consenso de como se tratar o tema. Visto que, a esfera político-administrativa não poderia revogar o combate ao preconceito de gênero, pois esse é um fenômeno relacionado com lutas pelo reconhecimento de identidades coletivas, que visam à proteção contra a opressão, a marginalização e o desrespeito a grupos minoritários. Então estrategicamente se promove a validade de discursos conservadores em questões de comportamento através do reconhecimento de discursos de dominação e justificação ideológica (HABERMAS, 1980, p.17). Intrigante observar, que no CONAE [2013] - durante o período de debate - conforme explicitado acima, 
a questão de gênero não foi desconsiderada. Ao contrário, o documento é bem específico a respeito da erradicação do preconceito de gênero, seu texto traz os semas 'machismo', 'homofobia', 'lesbofobia', 'transfobia', 'sexismo' entre outros. Essa preocupação em dar ênfase através da tipificação dos preconceitos, se dá em razão que os membros que ratificaram a importância de tais metas eram em números bastante expressivos de educadores, houve, também participação de educandos.

Portanto, conclui-se através de lentes mais espessas que é necessário ir além de simplesmente combater o preconceito de gênero, é necessário conhecer quais são para que assim propostas educacionais eficazes sejam elaboradas. Nesse diapasão, é que se pode firmar que apesar do CONAE ser uma instituição que visa o debate civil educacional, seu parecer foi excluído da decisão do poder legislativo no que concerne a égide do debate. A contrário senso do esperado o espaço público, que deveria ser usado para que o debate democrático pudesse se desenvolver criticamente e caminhar rumo ao esclarecimento, a retirada do termo 'gênero' dos PNEs foi feito às pressas e sem considerar a manifestação de convicções de um grupo legítimo para tratar do tema. Além disso não houve possibilidade de argumentação e busca de alternativas de superação de problemas que afligem há muito à sociedade (HANSEN, 1999, p. 74). O que nos leva a apreender é que sob a perspectiva comunicativa habermasiana essa questão ainda não foi exaurida e é por isso que muito ainda ecoa nos âmbitos das câmaras municipais, tais como leis julgadas inconstitucionais por proibirem tratar da questão (TEIXEIRA, 2017), municípios que tentam legitimar a questão em sala de aula (MARIZ; BRÍGIDO, 2017). Essa repercussão se deve à noção de movimento dialético hegeliano presente no pensamento de Habermas, que possibilita o questionamento de uma série de enunciados, mesmo que esses sejam tidos como verdadeiros em um determinado tempo cronológico, eles podem se mostrar falsos posteriormente ante a um novo enunciado. Isso porque esses enunciados baseados numa razão instrumental não produzem ainda a verdade já que foram produzidos no mundo da vida colonizado. A verdade produzida pelos enunciados proferidos pelo poder, que se localiza no sistema político sob a perspectiva estatal, embora se torne aparente ao nível de tradição cultural e disseminada como mudança estrutural no sistema de educação das crianças (BOURDIEU, 1989, p.66), aos poucos é possível que ela seja desmantelada conforme o despertar de um progresso qualitativo no nível de consciência.

Assim sendo, afirmar que a retirada do termo 'Gênero' leva à aniquilação de direitos é deveras prematuro, porém é inegável que o efeito do fenômeno da polêmica excluí a possibilidade de um debate que poderia corroborar para solidificar os pilares do pluralismo no estado democrático brasileiro. 


\section{CONCLUSÃO}

Mesmo que a investigação em tela se encontre em ainda em curso, é possível se estabelecer uma breve moldura dos debates que envolvam este marcador social a partir dos resultados obtidos nesta aferição. Buscou-se mapear através da pesquisa de campo realizada na ETEHL segundo o recorte inicialmente proposto, as aporias que se manifestam no interior do discurso, suas contradições e confluências em relação a uma grade ou moldura cognitiva simbolicamente estruturadas a priori, de acordo com as respectivas narrativas biográficas de cada sujeito. Sob o mesmo ponto de vista, as contribuições ofertadas por D. Maingueneau nos revela, de certa maneira, uma categoria de topos; ou como já afirmou P. Bourdieu alhures, um campo simbólico onde as subjetividades se esforçam a manter-se anelados aos dogmas que são próprios da codificação judaico-cristã, entretanto, apresentam, ao mesmo tempo, rupturas discursivas em relação ao mesmo sistema de crenças e latentes aos mesmos sujeitos quando os enunciados são postos vis-à-vis.

Os questionários aplicados em sala de aula, considerado aqui o universo investigado, também revelaram que as formações discursivas que permeiam os discursos midiáticos televisivos, tanto daqueles favoráveis quanto a dos desfavoráveis à discussão de gênero, são bem parecidas a dos entrevistados. Isso reforça a reflexão de que se faz relevante desenvolver no âmbito da formação escolar o princípio da competência discursiva, o qual "[...] permite identificar essa articulação discursiva e a capacidade dos Sujeitos de interpretar e de produzir enunciados que dele decorram" (MAINGUENEAU, 2008, p. 52). Esse é outro ponto significativo que não pode deixar de ser abordado na hipótese interdiscursiva. Ela faz alusão à imbricação tamanha, que existe entre o mundo, o discurso e a instituição, ela se dá de tal maneira que eles se fundem em uma mesma enunciação. Interessante notar que essa lógica institucional pode ser percebida com uma nitidez semântica notável. Nos questionários aplicados, por exemplo, houve expressões nítidas da presença de instituições religiosas. Ao responder à questão sobre a discussão de gênero na escola, um dos entrevistados respondeu que “era algo errado, e justificado pelo fato da bíblia dizer que homossexualismo é errado, porém, assim mesmo deveria acontecer o debate". Além disso, a pesquisa empírica também apontou a formação de um possível campo discursivo onde as pretensões de validade de cada ator observado adquirem uma determinada forma, e não obstante, são confrontadas por outros atores sociais ou e até mesmo falseadas de acordo com os certos símbolos. Em outras palavras, os discursos que superpõem são aqueles que pertencem aos sujeitos que compartilham 
concepções sociais em comum, caracterizando uma espécie de interferência construtiva nos discursos, e a contrario sensu, discursos divergentes tende a se anular, a saber, ensejando em um fenômeno antissimétrico ao primeiro. Outro ponto observado na pesquisa é o esforço de certas agências ligadas a movimentos que se autodenominam "conservadores" como a "Escola sem Partido" tendem a esvaziar a legitimidade discursiva do docente causada pela polêmica da questão do debate de gênero, inclusive, a judicialização do debate cada vez mais adquire maior corpo e forma e tende a ser mais acirrada, pois o conservadorismo que integra o interdiscurso das formações discursivas analisadas se fortalece e começa a ganhar "[...] notoriedade; recrutando simpatizantes capilarizados em diferentes camadas sociais" (LARANGEIRA, 2016, p.415) que alegam que as questões relacionadas a gênero rompem com os valores predominantemente cristãos na sociedade brasileira. Nessa perspectiva, uma outra reflexão que se depreende é que tais ações políticas colocam em tensão a liberdade de expressão e o livre trânsito dos saberes nos espaços escolares, e além disso podem "abrir um caminho na direção de um modelo totalitário de controle das discussões" (LARANGEIRA, 2016, p. 421), na qual o estado extrapola sua função de governar, interferindo-se, deste modo, na vida privada do cidadão e na construção de uma autonomia de pensamento. Estas agências trazem à existência sob o viés discursivo argumentos cientificamente respaldados, e propõem que o processo de construção da ideia de gênero esteja adstrito exclusivamente ao sexo cujas características são biologicamente imutáveis a fim de se constituir uma certa essência cujos os sentidos e os significados sejam atribuídas de acordo com os dogmas do cristianismo e do senso comum. Ademais ainda é possível inferir através desta pesquisa, que essa dicotomia comportamental de gênero não é só um produto cultural, mas também um produto de discursos científicos que exprime determinados interesses políticos e sociais. Tal regra comportamental pode ser encarada como fruto de um processo histórico marcado pelo poder, no qual a política estatal cristaliza o controle político sobre o corpo tendo como instrumento o saber científico (BUTLER, 1990). É nesse contexto da intercompreensão da polêmica, que o termo ideologia de gênero surge. Na tentativa de determinados grupos, especialmente o Movimento "Escola Sem Partido", disseminarem a falsa ideia que o debate de gênero na escola é uma forma de induzir à formação de sujeitos da diversidade sexual e de gênero. Ora pois, é como se a existência do conceito de gênero criasse na humanidade pessoas homossexuais, travestis, lésbicas, transgêneros, transexuais ou bissexuais, por exemplo. Seria possível inferir que o presente reuniu 'condições de possibilidades históricas' para que esse movimento conservador tomasse tamanha expressão em nossa sociedade? Seria muita pretensão analisar, nos últimos anos, o descontentamento com o governo federal associado à concentração de 
inúmeras críticas nos campos da economia, política e educação como um fator que favoreceu o surgimento e a união de forças conservadoras e tradicionais contra as políticas de igualdade, respeito aos direitos humanos e políticas afirmativas? Talvez essa seja uma questão que vá muito mais além da preocupação com a Educação. O que parece é que essa questão se torna com o passar do tempo muito mais complexa do que parece, mais ainda se essa análise for feita em consonância com a discussão dos distintos projetos de governo que vêm torneando a sociedade brasileira como solução sistêmica para uma dita crise econômica, que deixa amostra uma crise mais profunda que é a crise social que parece talhar as bases tão superficiais de um Estado Democrático de Direito que não teve tempo de se instaurar no âmbito da nação brasileira. 


\section{REFERÊNCIAS}

BOURDIEU, Pierre. O Poder Simbólico. Rio de Janeiro: Bertrand Brasil, 1989.

BUTLER. Judith. Problema de Gênero: Feminismo e Subversão da Identidade. 1990.

CONAE 2014: Conferência Nacional de Educação: documento - referência [elaborado pelo] Fórum Nacional de Educação. - Brasília: Ministério da Educação, Secretaria Executiva Adjunta, [2013].

FIORIN, José Luiz. Introdução à Linguística. São Paulo: Contexto, 2002.

FOUCAULT, Michel. Ditos e Escritos II: Arqueologia das Ciências e História dos Sistemas de Pensamento. 2013.

FOUCAULT, Michel. Microfísica do Poder. Rio de Janeiro: Record ,1998.

HABERMAS, Juergen. A Crise de Legitimação no Capitalismo Tardio. Rio de Janeiro: Tempo Brasileiro, 1980.

HANSEN, Gilvan Luiz. Modernidade, Utopia e Trabalho. Londrina: Eduel, 1999.

LARANGEIRA, Marcelo Farias. O Estado de Exceção como Limite da Liberdade Comunicativa nas Políticas Educacionais. In: Anais do $11^{\circ}$ Colóquio Habermas e $2^{\circ}$

Colóquio de Filosofia da Informação, Rio de Janeiro: Salute, 2016.

MAINGUENEAU, D. Gênese do Discurso. 2. ed. São Paulo: Parábola Editorial, 2008.

MARIZ, Renata e BRÍGIDO, Carolina. Jornal O Globo. Rio de Janeiro, 19/06/2017 disponível em https://oglobo.globo.com/sociedade/stf-suspende-lei-que-proibia-ensino-sobregenero-nas-escolas-do-parana-21491015 acesso em 27/07/2017 às 12:06.

ORWELL, George. 1984. São Paulo: Companhia das Letras, 2009.

TEIXEIRA. Fábio. Jornal O Globo. Rio de Janeiro, 16/01/2017 disponível em https://oglobo.globo.com/rio/bairros/vereadora-quer-derrubar-emenda-que-proibe-discussaode-genero-em-escolas-de-niteroi-20772979 acesso em 27/07/2017 às 12:09 